\title{
Does A Trading Simulation Exercise Enhance Financial Learning?
}

Rakesh Duggal, Southeastern Louisiana University Thomas Meyer, Southeastern Louisiana University

\begin{abstract}
This study investigates whether a bond trading simulation enhances student learning. Using traditional instructional methods, two groups of students are taught the basic principles of bond valuation. One of the two groups also participates in a simulation exercise. Both groups are given a test to assess their learning. The study does not find evidence that a bond simulation exercise has any significant impact on student learning, as measured by the test. The study, however, does find a significant relationship between a student's GPA and his/her performance on the test.
\end{abstract}

Keywords: Simulation, trading

\section{INTRODUCTION}

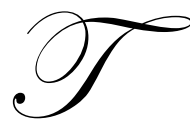

raditional methods of financial instruction include lectures and problem solving. Recently, due to the various technological innovations and their declining costs, business schools have been increasingly employing technology in the instruction of finance. Many schools have set up a finance lab, also called a trading room, for this purpose. A lab is generally equipped with ticker tapes, data boards, Bloomberg terminals, and computers equipped with various software for performing diverse financial activities, including security analyses, portfolio management, and risk analyses (Alexander, Heck, and McElreath 2000). In addition, with a simulation software package, the lab can be converted into a trading room and students can learn financial concepts through trading securities among themselves ${ }^{1}$. A simulation package is quite expensive and the annual licensing fee can be as high as $\$ 7,500$. However, there is no hard evidence to date that trading simulations enhance learning ${ }^{2}$. This study employs a basic bond valuation simulation exercise to provide evidence on the usefulness of simulations in financial learning.

A typical simulation package provides several cases covering various types of securities such as bonds, stocks, foreign currencies, options, and futures. An instructor teaching bond valuation, for example, first covers the theory and provides all essential information to his students. Then the instructor exposes the students to the case. In a basic bond case, half the students are given $x$ number of zero coupon bonds and the rest are given $y$ number of coupon bonds. In addition every participant receives some cash. Short selling and borrowing are allowed. Students are provided information on the prevailing interest rates and maturities. The objective for the students is to make the most amount of money by recognizing trading opportunities based on market misvaluations. Students trade the bonds $n$ times during a simulation exercise (where, $n=$ the initial maturity of the bonds), once at the start of each year for a four-minute period. They may choose to enter their bid and/or ask prices and the quantities of bonds they want to buy or sell. They can also trade at the best bid and ask prices displayed on their monitors. Additionally, they have the option to not trade, in which case their idle funds will earn the stated rate of return. At the end of the exercise the program calculates the total amount of money in each student's account and students find out how they performed.

\footnotetext{
${ }^{1}$ Financial Trading Software is one such web-based software package. In addition to case-based simulation exercises, the package offers modules to value and analyze equities, fixed income securities, and derivatives.

${ }^{2}$ Ascioglu and Kugele (2005), after conducting an equity simulation exercise, surveyed their students. They report that the students enjoyed the simulation exercise and learned from it.
} 


\section{STUDY DESIGN}

The above simulation exercise does not provide any new knowledge on bond valuation to students. It, however, has the potential to spark their interest in the subject matter, and also provides them an opportunity to practice what they have learned, thereby enhancing learning. In particular, through this exercise, they may better understand many underlying concepts, such as bid-ask prices, coupon rates, maturities, yield to maturity, and most importantly, valuation.

The experiment involves six sections of Business Finance, the first junior-level finance course required of all business students, spanning one academic year. The students in all of the sections receive instruction from the same instructor on the principles of bond valuation, including par value, coupon rate, current yield, yield to maturity, bid-ask prices, valuation, and market efficiency. In addition, the impact of changing interest rates and time to maturity on bond values is also illustrated by examples. After covering the basic material through lectures and problem solving, the control group comprising three sections is given the appended timed test. Students are informed in advance that they will take a test on bond valuation. All questions on the test are equally weighted. Students receive a maximum of 10 points toward their course grade for their performance. The test also gathers information on the students' GPA, junior/senior status, major, and their self-reported interest in finance to be used as control variables (see Appendix). The simulation exercise is conducted in the experimental section ensuring that no additional information or emphasis is provided on the subject matter. The control group, which also comprises three sections, takes the same test but without the simulation exercise.

The study uses the means tests and logistic regressions to test the null hypothesis that the bond simulation exercise does not enhance learning. In terms of the study design, it is hypothesized that there will be no difference in the mean test scores of the two groups. SCORE, the dependent variable, is assigned a value of 1 if the student's test score is higher than the median score of the control group, and zero, otherwise. The following variables are used as control variables:

$\mathrm{GPA}=$ Cumulative grade point average

MAJOR $=$ a dummy variable (Finance $=1$; all other majors $=0$ )

SIMULATION $=$ a dummy variable $($ Simulation exercise $=1 ; 0$, otherwise $)$

SENIOR= a dummy variable (Senior $=1 ; 0$, otherwise)

INTEREST $=$ a dummy variable (very interested in the class $=1 ; 0$, otherwise)

The four control variables, GPA, MAJOR, SENIOR, and INTEREST are expected to be positively related to SCORE. A higher GPA reflects the student's overall academic caliber. Finance majors, due to their possible prior preparation, may be expected to perform better than non-finance majors. Likewise, seniors, due to the amount of college work done, may also be better prepared for the finance class. Finally, INTEREST captures each individual's subjective perception of the class and class materials and may affect a student's learning and score.

\section{FINDINGS}

Table 1 contains univariate statistics for the two groups of students, the control group (70 students) and the experimental group (82 students). Analysis of the data shows that the average score of the experimental group is higher than that of the control group. However, the difference is statistically insignificant. The experimental group contains more seniors than the control group and the difference is statistically significant at the .01 confidence level. The control group is exclusively comprised of non-finance majors and has a higher average GPA and a higher selfreported interest in the course than the experimental group. None of these differences, however, prove to be statistically significant. Overall, if seniors are presumed to be more academically prepared for the finance class, then the study may be biased against rejecting the null hypothesis of no impact of the simulation exercise on student learning.

Table 2 contains results from a logistic regression. The coefficient of SIMULATION is positive but insignificant. The only variable with a significant coefficient is GPA: A higher student GPA is associated with a 
higher probability that the student will perform better than the median performance of the control group. More precisely, the log of the odds of a student performing better than the control group, after controlling for the effects of other variables, rises by 1.99 times the student's GPA.

It is possible that high GPA students benefit more from a simulation exercise than a low GPA student. To test this interaction effect of GPA and SIMULATION, an interaction term is added to the model. The results remain unchanged (not reported).

\section{CONCLUSION}

This study does not find any link between a bond trading simulation exercise and financial learning. However, some limitations of the study design must be noted. First, the study design is biased in favor of the experimental group: The participation in the simulation exercise provides students an additional learning opportunity, potentially enabling them to perform better on the test. Second, the study does not capture the effects on learning of long-term use of simulation exercises. It is conceivable that repeated use of simulation exercises covering different topics will enhance student familiarity with this technology and learning over time. Finally, the study does not measure the experiential value to students of making quick trading decisions under the "real-time" pressure.

\section{REFERENCES}

1. Alexander, John C. Jr, Charles C. Heck, and Robert B. McElreath, A Guide to Building a University Trading Room, Financial Services Review, volume 10, No. 3, Autumn 2000, p.209-220

2. Ascioglu, Asli and Lynn Phillips Kugele, Using Trading Simulations to Teach Market Microstructure Concepts, Journal of Financial Education, Summer 2005, p. 69-81

3. Spector, Lee C. and Michael Mazzeo, Probit Analysis and Economic Education, Journal of Economic Education, Spring 1980, p37-44.

\section{Table 1}

Means, standard deviations, and t-statistics for the difference in means for the five variables of interest for the two groups of students. The variables are: SCORE (the student's score on the test), GPA (the student's cumulative grade point average), INTEREST ( $=1$ if the student is very interested in finance and 0 , otherwise), SENIOR (=1 if the student has 90 credit hours and 0, otherwise), and MAJOR ( $=1$ if the student's major is finance and 0, otherwise).

\begin{tabular}{|l|l|l|l|}
\hline Variable & $\begin{array}{l}\text { Experimental Group } \\
\text { Mean (standard deviation } \\
\text { in parentheses) } \\
\mathrm{n}=82\end{array}$ & $\begin{array}{l}\text { Control Group } \\
\text { Mean (standard deviation } \\
\text { in parentheses) } \\
\mathrm{n}=70\end{array}$ & $\begin{array}{l}\text { t-statistic for the difference } \\
\text { in means }\end{array}$ \\
\hline Score & $44.15(22.00)$ & $41.21(18.07)$ & 0.90 \\
\hline GPA & $2.95(0.50)$ & $2.96(0.55)$ & -0.16 \\
\hline INTEREST & $0.29(0.46)$ & $0.44(0.50)$ & -1.91 \\
\hline SENIOR & $0.55(0.50)$ & $0.39(0.49)$ & $2.02^{*}$ \\
\hline MAJOR & $0.07(0.26)$ & $0.07(0.25)$ & 0.19 \\
\hline
\end{tabular}

*Significant at the .05 confidence level. 


\section{Table 2}

Results from a logistic regression. The independent variable is SCORE ( $=1$ if the student's score on the test is greater than 40 , the median for the control group, and 0, otherwise). The dependent variables are: SIMULATION (=1 if the student participated in the simulation game and 0 , otherwise), GPA (the student's cumulative grade point average), INTEREST (=1 if the student is very interested in finance and 0 , otherwise), SENIOR $(=1$ if the student has 90 credit hours and 0 , otherwise), and MAJOR ( $=1$ if the student's major is finance and 0 , otherwise).

\begin{tabular}{|l|l|l|}
\hline Variable & Estimate & Wald Chi-Square (probability) \\
\hline INTERCEPT & -3.89 & $10.77(.00)$ \\
\hline SIMULATION & 0.32 & $0.76(.38)$ \\
\hline GPA & 1.99 & $10.54(.00)$ \\
\hline INTEREST & -0.03 & $0.01(.94)$ \\
\hline SENIOR & -0.43 & $1.32(.25)$ \\
\hline MAJOR & 0.28 & $0.18(.68)$ \\
\hline
\end{tabular}

Wald model Chi-Square: 15.39 (significant at 0.01 level)

\section{Appendix}

\section{Bond Valuation Test}

Please provide the following information.

I. Student ID:....

II. My cumulative GPA is

III. I am a...major
A. Finance
B. Accounting
C. Management
D. General Business

IV. I am a
A. senior
B. junior

V. I am... interested in this class
A. very
B. somewhat

Choose the best answer from those given for the following 10 questions. You have $\mathbf{1 5}$ minutes.

Questions 1-4 are on the following data:

A bond pays you $\$ 120$ in interest every year. The face value of the bond is $\$ 1,000$ and it will mature after 20 years. The yield to maturity (YTM) on similar bonds at present is 10 percent,

1. What is the value of this bond?
A. $\$ 1,000$
B. $\$ 1,100$
C. $\$ 1,170$
D. $\$ 1,175$ 
2. The coupon rate of the above bond is
A. $\quad 10$ percent
B. $\quad 12$ percent
C. not given and cannot be ascertained
D. None of the above

3. If the yield to maturity on similar bonds declines, the above bond will sell for...now
A. the same amount as the answer to question \#1.
B. lower than the answer to question\#1 above.
C. $\$ 1,000$
D. None of the above

4. Fast forward to next year. The remaining maturity is 19 years now. Assuming no change in the yield to maturity (YTM) on similar bonds, the above bond will be ... in value.
A. lower
B. higher
C. the same
D. None of the above

5. The best bid price available for a bond is $\$ 1,150$. This means that you can
A. buy this bond for $\$ 1,150$.
B. sell this bond for $\$ 1,150$.
C. buy or sell for $\$ 1,150$, depending upon your need.
D. None of the above.

6. The best ask price for a bond is $\$ 1,145$. This means that you can
A. buy this bond for $\$ 1,145$.
B. sell this bond for $\$ 1,145$
C. buy or sell for $\$ 1,145$, depending upon your need.
D. None of the above

7. The correct price of a bond is $\$ 1,165$. The best available bid price and ask price are $\$ 1,167$ and $\$ 1,167.25$, respectively. You have a trading opportunity for a brief time period before the market prices the bond correctly. Ignoring transaction costs, you should
A. buy the bond
B. sell (or short sell if you do not possess) the bond
C. do nothing
D. None of the above

8. What is the yield to maturity (YTM) of the following bond?

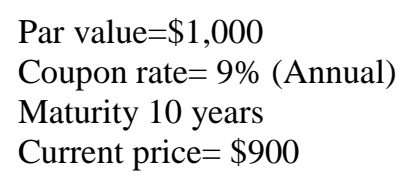



A. $\quad 10.67$ percent
B. $\quad 11.00$ percent
C. $\quad 11.67$ percent
D. 12.67 percent

9. The current yield of the bond (in \#8 above) is
A. 9 percent
B. $\quad 10$ percent
C. $\quad 11.67$ percent
D. inderminate.

10. If a AA-rated bond's yield to maturity is 10 percent and a 26 -week t-bill is paying a 10 percent annual return, then, assuming risk aversion, you would
A. invest in the AA-rated bond.
B. invest in the t-bill
C. be indifferent between the two choices
D. None of the above

\section{NOTES}

